\title{
Exploring the Economic Transformation in the Era of Big Data
}

\author{
Ni Keqin \\ Wuhan University of Technology \\ Wuhan, Hubei \\ 1003559534@qq.com
}

\begin{abstract}
Since the reform and opening up, China's GDP has achieved a steady growth, but this "steady growth" can no longer be supported by the traditional extensive development model. The problem of how to transform the economic model has become an important strategic challenge for the country's economic development. While applying various methods of economic transformation, we must pay attention to highlighting the individualized characteristics of China's big data era, so as to adapt to the current New Normal background. Based on the background of the big data era, this paper analyzes the changes brought about by big data, and demonstrates in detail the way to change China's economic development in the era of big data.
\end{abstract}

Keywords-Big data; Economic development mode; Transformation; Business

\section{INTRODUCTION}

Big data, refers to the massive, high growth rate and diverse information assets that require new processing models to have greater decision making, insight and process optimization capabilities. Broadly speaking, big data is a collection of large amounts of data that cannot be collected, analyzed, and managed with normal software tools for a certain period of time.

The topic of big data was first mentioned by Toffler in the Third Wave of 1980. The discussion of big data before 2011 was basically limited to the computer field. In May 2011, EMC and IDC collaborated on the "Digital Universe" research. Five years later, the concept of "big data" was formally proposed. Later, consulting companies such as McKinsey actively promoted this concept [1]. In March 2012, the US government raised big data to the national strategic level, and big data gradually attracted attention. With the Internet as the carrier, the conception and application of cloud computing, Internet of Things, smart earth and other concepts, data collection, storage, processing and application have entered a new stage of development. Once again, the development of productivity has brought human society into a new era of development--Big Data Era. The era of big data has changed the constraints of economic and social development and has driven new reforms in the economy and society [2].

\section{Big DATA CHANGES}

In the past 30 years of reform and opening up, China has relied on the investment of cheap labor, high-consumption resources and large-scale government investment to achieve rapid economic growth, but the weakness of the tertiary industry has made the industrial chain of economic development relatively low; due to income distribution unevenness and various reasons such as difficulty in seeing a doctor, difficulty in buying a house, etc. affect domestic consumption and domestic demand; at the same time, the difficulty of financing and the difficulty of loans have caused China's small business operators to be unable to start businesses due to lack of circulating funds. The emergence of big data can improve the status quo of economic stagnation. McKinsey has also done research on big data, and pointed out that the application of big data has penetrated into all walks of life, has gradually become an important production factor, and is impetus for productivity improvement. Big data applications, including financial investment, human resource management, marketing, supply chain management and health care, customer relationship management, food and medical, etc., have become important factors in maintaining social development.

\section{A. Big data and market funds}

Investment, domestic demand and exports are the three troikas that drive China's economic growth. For the economic transformation, adjusting the economic structure and improving investment efficiency are the key points. In addition to the introduction of foreign capital and the establishment of joint ventures, many financing methods are also implemented. For example, the development of e-commerce platforms has accumulated massive amounts of data on these Internet masses. The information is mined and analyzed, and the rules are more realistic than the data released in reality. In 2010 and 2011, Alibaba opened two small loan companies, and the target customers were limited to registered member merchants of Alibaba e-commerce platform. All loan procedures have been completed online. Alibaba's Ali Finance has set an average of nearly 10,000 loans per day. Since 2010, it has invested a total of 28 billion yuan to provide financing service $f$ or more than 130,000 small and micro enterprises and individual entrepreneurs. Loan non-performing rate is controlled within $1 \%[3]$ 
At the same time, big data has improved the flexibility of bank loans. Traditional bank loans follow the "two-eighth law", which fully supports $20 \%$ of high-end users, while they choose to give up $80 \%$ of low-end users because of weak profits, but this is a fatal blow for Economic development, especially for the re-production of self-employed and small traders. For this reason, some banks have introduced micro-loans to solve such problems, such as Minsheng Bank's micro-loans. As of the end of September 2013, the bank's small and micro enterprise loan balance reached 404 billion yuan, and a total of 1.2 trillion small micro loans were issued in the past five years, reaching 1.7 million micro enterprise customers. The loan nonperforming rate was effectively controlled at $0.52 \%$. Credit considerations stem from the massive data or operating bills of their networks, which is of great significance for financing and corporate reproduction.

\section{B. Big Data promotes enterprise innovation}

In the era of big data, in order to obtain rich information, the data must be deeply explored and analyzed, and enterprises can greatly benefit from it. Bill Franks's "Control Big Data" provides readers with vivid examples, the "big data" records of the online shopping, and automobiles insurance industry, machinery manufacturing, power industry, gaming industry, online games and other industries will be used by enterprises to predict the market. With these data sources, companies can segment customers and dig customers demand and marketing strategies more accurately, and can predict the behavior of potential customers, improve customer loyalty and adhesion to products, and enhance the competitiveness of enterprises. Enterprises are the cells of the market economy. The healthy development of each enterprise will promote the steady growth of the economy, and the flexible operation mode of enterprises will inevitably become the lubricant of economic transformation. Consumers who buy diapers in the Wal-Mart supermarket chain in the United States will buy beer by the way. This is because after the work, the husband is asked by his wife to buy the diaper and at the same time he will buy the beer he likes.

Ma Yun used the strong correlation between Alibaba's "Big Data" enquiry index and the transaction index to successfully predict the 2008 financial crisis, and the timely update of Taobao "CPI" allowed him to successfully predict inflation and effectively avoid investment risks. Marketing, while profiting the business owner, also stimulates the country's domestic demand, providing an effective way to promote consumer purchasing power.

\section{Big data promotes industrial upgrading}

Economic transformation is freed from the extensive model, breaking through the cage of low returns, which requires the state to support the emergence of new industries. The emergence of big data has also led to emerging industries information aggregation platforms, which use massive amounts of network data mining, then build data models, and provide data sources or data analysis to enterprises through charts or other forms. The economic value of big data in the future will also increase day by day. These data will be composed of data providers, managers, regulators, and implementers like infrastructure. The combined use of data will become a major industry.

Still taking Alibaba as an example, Alibaba has more than 100 data analysts who analyze different data in different departments, analyze data sharing, and form collaborative data analysis with data administrators and corporate management. GNIP can provide API aggregation for social networks and mine web data for sites such as WordPress, Twitter, Sina Weibo, and Facebook. Ai Rui can provide network behavior monitoring data. The sample includes 200,000 Chinese netizens. The sample covers more than 1000 software and more than 3,000 websites. These have undoubtedly promoted the prosperity of emerging industries and promoted the reorganization and composition of business models.

\section{Talent demand in the era of big data}

According to the theory of economic mountain effect, we can see the importance of talent. The mountain effect is the height reached by some mountains in natural life. According to the objective law of nature, the theory of mountain effect is constructed, that is, the mountain body represents the economic and social whole of a country or region, and a mountain line is used to express the imbalanced labor development intelligence level in the whole. The high point of this mountain line is the mountain top. The Department expresses the overall level of economic and social development, and represents the highest level of labor development in this country or region in the real economic society. This determines the overall level of development of the economy and society [4]. In the era of big data economy, it is especially necessary to analyze the composite talents of the economy and big data. Therefore, the cultivation of high-tech talents is also an important step in the economic transformation. McKinsey predicts that the United States may lack 140,000-190,000 analytical talent in 2018, and lack of management and analysts who know how to use the tools to analyze big data and make sound decisions. Niu Qinyu, business manager of China E-commerce Alibaba, said, "There is no shortage of data mining talents in China, but it is difficult to find data scientists." A country's labor literacy is directly related to the national economy, so cultivating new high-end talents is an urgent strategic deployment.

\section{THE TRANSFORMATION OF CHINA'S ECONOMIC DEVELOPMENT MODE IN THE ERA OF BIG DATA}

The mode of economic growth is "the way in which the distribution, input, combination and use of factors of production". The content of the economic development mode is richer than the economic growth mode. It not only pays attention to the economic growth rate, the efficiency and stability of economic growth, but also pays attention to income distribution, innovation ability, resource utilization and ecological environment. The addition of new production factors in the era of big data has changed the pattern of production factors. At the same time, relying on the Internet, the platform for resource allocation has been extended, the input, combination and use of traditional resources have been changed, and the transformation of economic growth mode to intensification has been accelerated. The pace has also promoted the transformation of the way the economy develops. 


\section{A. Changes in the combination of production factors in the era of big data}

Different stages of social development, the allocation of production factors are different, and thus determine the differences in the production, exchange, distribution and consumption of social wealth and economic growth patterns. From the traditional agricultural society to the information age, the structure of production factors has experienced the evolution of "labor + land", "labor + land + capital" $\rightarrow$ "labor + land + capital + technology (information, knowledge)". In the era of big data, data has become an important production factor, and the structure of production factors has been further expanded to "labor + land + capital + technology (information, knowledge) + data". At different stages of development, the role of different production factors in the production process is not the same. In the era of agricultural economy, natural resources such as land have become the leading factor in social production; in the era of industrial economy, capital is the dominant factor. In the information age, knowledge and technology gradually replace capital as the dominant factor in social production. In the era of big data, data analysis and data processing application capabilities have become the dominant factors in social production, and have also changed the traditional industry form and derived new industrial forms.

\section{B. Changes in production patterns in the era of big data}

Production mode refers to a general summary of the producer's organic, effective combination and operation mode of the input resource elements, production process and output. The differences in the level of development of science and technology and the degree of marketization in different periods have all played an important role in the transformation of production models.

The era of big data relies on mobile internet, cloud computing, and the Internet of Things, making it possible to integrate the industrial economy with the information economy. Producers and users have realized rapid exchange of information through online network and interactive networking. The distance between the two parties has almost disappeared, changing the traditional "demand-design-manufacture-sales and service" production mode, which is more efficient and high. Flexible production models are the future. Its main features are accurate production, custom production and open production.

- The first is the transformation from B2C to C2B. Users and producers directly link through the network to set production, realize zero inventory and zero backlog, and achieve accurate production.

- Second, the application of digital technology, user demand has become the basis of producer production, personalized intelligent production has become a trend, and custom production has been realized.

- The third is multi-dimensional information feedback, enabling producers to understand user experience data in a timely manner, correcting current $R \& D$ and production activities through data analysis, and enhancing the openness of the entire production process.

\section{Changes in consumption patterns in the era of big data}

Consumption is an important aspect of people's social lifestyle. Consumption patterns have both natural and social attributes.

From the perspective of the natural attributes of consumption patterns, traditional consumption methods are typical offline consumption, and people rely on physical consumption places for consumption. In the era of big data with the Internet as the main carrier, the consumption pattern has realized the transition from offline consumption to online consumption, and from online consumption to online and offline $(\mathrm{O} 2 \mathrm{O})$ converged consumption. Online consumption not only reflects the efficiency of the Internet, but more importantly, massive consumption of big data is recorded and stored. After the analysis of cloud computing, enterprises will understand the true face of consumption more than consumers themselves. Online and offline consumption has become a trend in the future. Relying on the Internet to reach a consumption agreement, substantial consumption is realized offline. This model organically combines online information inquiry, price comparison, payment and offline experience, and consumption. It accelerates efficiency and visualizes offline activity data.

From the perspective of the social attributes of consumption patterns, the relationship between consumers and suppliers has evolved from a one-way consumption and supply relationship to a multi-dimensional interaction relationship based on mobile Internet, namely consumers and producers, consumers and suppliers, A multi-directional interactive network of social relationships between consumers and consumers.

\section{SUMMARY}

In summary, in the era of big data, subverting the traditional business model must be sufficiently personalized, which will become the ultimate goal and new driving force for future business development [5]. Big data is not just a technological change, but more of a technology application service. This technological change and technology application service has changed the way the economy develops. At present, China's economy is in the new normal background. The core issues of the new normal are economic restructuring, economic development mode transformation and technological innovation. Therefore, in the new normal background, we must take the path of economic development mode according to the characteristics of the big data era, take big data as the core, strengthen the application of big data, establish a big data network, and deepen the transformation of the development mode of the big data era [6]. 


\section{REFERENCES}

[1] Lu Shengjun, Wang Zhongjun, Li Lin. Qian Xuesen's Intelligence Thoughts from the Perspective of Cyberspace and Big Data[J].Information Theory and Practice,2013(4). (In Chinese)

[2] Zheng Lingwei. Stride into "Big Data" Times [J]. Informatization Construction, 2013(1). (In Chinese)

[3] MCAFEE, EBRYNJOLFSSON.Bigdata: the management revolution [J]. Havard Business Review, 2012 (10).

[4] Qian Jin. Labor Utility Theory [M Beijing. Social Science Literature Publishing House, 2005. (In Chinese)

[5] Guo Guoqing, Qian Minghui. General Theory of Marketing (Fourth Edition) [M]. Beijing: Renmin University of China Press, 2011. (In Chinese)

[6] Big Data Across The Federal Government [EB/OL]http://www.whitehouse.gov/sites/default/files/microsites/ostp/ big_data_fact_sheet. Pdf, 2013-01-24. 